\title{
TECNOLOGIAS DE GÊNERO E MAGIA: HORMONIOTERAPIA E AS EXPERIÊNCIAS DE VIDA DE MULHERES TRANS*
}

\author{
André Filipe dos Santos Leite* e Claudiene Santos
}

\section{Resumo}

Analisamos a relação entre os hormônios e as experiências de vida de mulheres trans* como um aspecto simbólico do caráter místico que o aparato da saúde pode assumir, especialmente quando suas projeções políticas apontam para uma perspectiva despatologizante dessas experiências. Por meio de uma perspectiva metodológica queer alinhada a elementos da analítica do discurso foucaultiana, argumentamos, a partir de entrevistas e observação de cinco mulheres trans*, que o hormônio, através de uma narrativa mitológica, torna-se um agente social e político que, mesmo inumano, inventa possibilidades de humanidade ao instaurar tecnologias de gênero particulares no processo de cuidado em saúde das mulheres trans*. Observamos, deste modo, como as mulheres trans* se inventam nessa relação com os hormônios e como os processos de subjetivação ocorrem.

Palavras-chave: Saúde, hormônios, trans ${ }^{*}$, tecnologias de gênero

\begin{abstract}
Gender Technologies and magic: hormonotherapy and trans* women's life experiences

We analyzed the relation between the hormones and the life experiences of trans* women as a symbolic aspect of the mystique character that the health system can assume, specially when its political projections signal a possible depathologization of life experiences. Through a queer methodological perspective, aligned with elements from the Foucauldian discourse analysis, we suggest, based on the interviews and the observation of five trans* women, that the hormone, with its mythic surrounding narrative, becomes a social and political agent that, notwithstanding being nonhuman, creates possibilities of humanity by instituting unusual gender technologies while providing health care services to trans* women. In this way, in this relation with the hormones, we observe how trans* women recreate themselves and how the subjectivation processes happen.
\end{abstract}

Keywords: Health, hormones, trans*, gender technologies

* Departamento de Biologia/DBI da Universidade Federal de Sergipe, São Cristóvão - SE, 49100-000 , Brasil.

Endereço postal: Departamento de Biologia/DBI. Universidade Federal de Sergipe. Av. Marechal Rondon, s/n - Jd. Rosa Elze, São Cristóvão - SE, 49100-000, Brasil.

Endereço eletrônico: andrefsleite@yahoo.com.br

** Departamento de Biologia/DBI da Universidade Federal de Sergipe, São Cristóvão - SE, 49100-000 , Brasil.

Endereço postal: Departamento de Biologia/DBI. Universidade Federal de Sergipe. Av. Marechal Rondon, s/n - Jd. Rosa Elze, São Cristóvão - SE, 49100-000, Brasil.

Endereço eletrônico: claudienesan@gmail.com 


\begin{abstract}
Resumen
Tecnologías de género y la magia: la terapia hormonal y las experiencias de vida de las mujeres trans*

Analizamos la relación entre las hormonas y las experiencias de vida de mujeres trans* como un aspecto simbólico del carácter místico que el aparato de la salud puede asumir, especialmente cuando sus proyecciones políticas apuntan hacia una perspectiva de despatologización de esas experiencias. Por medio de una perspectiva metodológica que se alinea a elementos de la analítica del discurso foucaultiana, argumentamos, a partir de entrevistas y observación de cinco mujeres trans*, que la hormona, a través de toda una narrativa mitológica a su alrededor, se convierte en un agente social y político que, a pesar de inhumano, inventa posibilidades de humanidad al instaurar tecnologías de género particulares en el proceso de cuidado en salud de las mujeres trans*. En este sentido, observamos como las mujeres trans* se inventan en esa relación con las hormonas y como los procesos de subjetivación ocurren.
\end{abstract}

Palabras clave: Salud, hormonas, trans*, tecnologías de género

\title{
Notas introdutórias
}

Antiandrógenos, estrógenos e progestógenos. Perlutan, ciproterona e gestadinona. Cicloprimogyna, estradiol e depoprovera. Vistas assim, desprovidas de contexto parecem até palavras aleatórias que não revelam muita coisa. Talvez signifiquem um pouco mais quando citadas em congressos de endocrinologia, ao serem manipuladas em laboratórios químicos ou quando manuseadas pela indústria farmacêutica. Contudo, quando essas palavras circulam para além desses espaços, habitando esquinas, adentrando fóruns de discussão pela Internet, constituindo parte do repertório de vida de determinadas pessoas, muito da sua higiene é deixada para trás. Quando suturadas às experiências de vida de mulheres trans*, essas simples palavras tomam uma outra materialidade e cria-se um contexto que coloca o próprio estatuto de significação da saúde em disputa.

Utilizamos o termo trans* com um asterisco para, dessa forma, torná-lo mais abrangente, incluindo múltiplas expressões e identidades de gênero, como: trans, transexual, transgênero, travesti, etc. (Platero 2014; Tompkins 2014). O que o asterisco aporta é assinalar a heterogeneidade, ao conceber o corpo, a identidade e as vivências que vão além das normas binárias impostas. Trans*, trans e transgênero são termos que têm em comum serem eleitos pel*s própri*s protagonistas, diante daqueles que provêm do âmbito médico e que assinalam uma patologia. $\mathrm{O}$ asterisco quer especificar que podem existir lutas comuns e, ao mesmo tempo, reconhecer que há muitas outras questões nas quais não há um consenso ou uma visão única do que se supõe ser trans, trans*, transexual ou transgênero (Platero 2014; Tompkins 2014), além de incluir identidades como gêneros neutros, intersexuais, agênero, dois-espíritos, travestis e gêneros fluidos (Kilerman 2012 citado por Tompkins 2014). A forma trans* possibilita também o significado mais profundo do 
que poderia sugerir o próprio prefixo e se opondo a uma única forma legítima de referir-se às identidades e comunidades trans* (Tompkins 2014: 27).

Assim, neste artigo, analisamos a relação entre os hormônios e as experiências de vida trans*, entendendo o processo da hormonioterapia como um tipo particular de tecnologia de gênero (Lauretis 1994), ou seja, um aparato material e simbólico que constrói determinadas imagens de «homens» e «mulheres», e que atua na produção do que é culturalmente entendido como masculino e feminino. Para Lauretis (1994), o gênero não é uma propriedade dos corpos nem algo que existe $a$ priori nos seres humanos, mas é um conjunto de efeitos produzidos nos corpos, comportamentos e relações sociais. De tal modo, investigamos como essa relação das mulheres trans ${ }^{*}$ com o uso dos hormônios pode inclusive ilustrar um aspecto simbólico de um debate mais amplo do campo da saúde, o caráter místico, que a própria saúde assume em alguns contextos, e suas possibilidades de desterritorialização, quando pensamos alternativas de se fazer um cuidado em saúde que preze a despatologização das experiências trans*.

Entendendo os processos metodológicos como «uma certa forma de interrogação e um conjunto de estratégias analíticas de descrição» (Larrosa 1994, 37), que se referem a um «como fazer» (Reis 2012), a um como fazemos nossas pesquisas; tomamos como base um projeto metodológico que alberga uma perspectiva queer (Browne e Nash 2010) suturada a elementos inspirados na analítica do discurso de Michel Foucault $(1996,2005,2009)$. Afinal, se o queer se propõe a pensar os sujeitos e as subjetividades como projetos fluidos, instáveis, inacabados e que se fazem continuamente e indefinidamente em movimento, é por intermédio de uma analítica do discurso de inspiração foucaultiana que podemos pensar criticamente sobre as construções históricas, culturais e sociais estabelecidas nas relações de saber-poder que construíram a ideia dessas pessoas e subjetividades como estáveis e imutáveis.

Assim, a partir de cinco entrevistadas ${ }^{1}$ que se autodenominaram mulheres trans ${ }^{*}$ e de observação acompanhante de suas trajetórias de vida, argumentamos que o hormônio torna-se um agente social e político que, mesmo inumano, inventa possibilidades de humanidade ao instaurar tecnologias de gênero particulares no processo de cuidado em saúde. A aproximação com as entrevistadas deu-se inicialmente a partir do contato com uma organização não-governamental, e posteriormente por meio de indicações umas das outras (bola de neve), tendo todas as participantes assinado o termo de consentimento livre e esclarecido (TCLE) autorizando a utilização das informações para a pesquisa.

Observamos, no transcorrer das entrevistas, como as mulheres trans* se inventam na relação com os hormônios e como os processos de subjetivação ocor-

Trata-se de um desdobramento da pesquisa intitulada «Mulheres transexuais: vivências, histórias e narrativas de vida na transexualidade», com financiamento do Programa Institucional de Bolsas de Iniciação Científica (PIBIC)/CNPq. 
rem, tanto na ordem da transformação física, quanto produzindo novos contextos discursivos e práticos sobre o que insistimos em chamar de saúde. Nesse ponto, a digressão apresentada pelas mulheres trans* quanto a relação que estabelecem com os hormônios permite-nos pensar em contextos que tomam essas experiências em outros espaços, que se opõem ao território da patologia.

Dessa forma, evidenciamos que as demandas e litígios pelo acesso aos hormônios não representam apenas um desejo de transformação do corpo, mas que esse processo de disputa coloca todo um projeto hegemônico de saúde em jogo, que envolve (re)pensar o estatuto de patologia a que essas pessoas são remetidas quando não só pervertem e subvertem o uso dos hormônios, mas, especialmente, quando lhes endereçam esse caráter mágico de produção corporal.

\section{Corpos hormonais e a produção do feminino}

Dentre as várias substâncias que percorrem isso que chamamos de corpo, os hormônios parecem assumir um aspecto bastante singular. Inicialmente, descritos pela fisiologia como mensageiros químicos responsáveis pela regulação da atividade de diversos tecidos. Depois, apropriados pela farmacologia na forma de cápsulas, comprimidos, pílulas, soluções injetáveis, emplastros, géis, etc. E assim, portanto, passíveis de serem utilizados pela clínica na transformação física dos corpos, seja o GH no nanismo, o T4 nas tireoidites, o estradiol na menopausa, a insulina no diabetes e assim por diante. Os hormônios, contudo, guardam endereçamentos outros, que vão além da regulação das funções fisiológicas de um pretenso maquinário humano e que prescindem os compostos estabilizados da farmacologia, utilizados pela clínica em suas prescrições terapêuticas de transformações morfológicas. Os hormônios também circulam em nossos imaginários, endereçam condutas, atravessam subjetividades, formatam ficções e constroem sonhos, que a todo custo se procura serem vividos.

Assim, ao acessarmos uma receita médica que prescreve: «1 comprimido de $1 \mathrm{mg}$ de estradiol associado a 1 comprimido de $50 \mathrm{mg}$ de acetato de ciproterona por dia», para Sara, uma de nossas entrevistadas - sob a indicação de que com seu uso ela conseguiria as transformações físicas que tanto almejava -, parece que estamos diante desses outros endereçamentos dos hormônios, que prescindem a higiene médica e a expertise clínica. Tais transformações físicas, tão desejadas por Sara, e que motivam a prescrição médica dos referidos compostos hormonais, visam à construção de um corpo marcado por signos próprios daquilo que, historicamente, vem sendo entendido como feminino. De tal modo, os hormônios prescritos figuram como possibilitadores de uma materialidade do próprio feminino e, é como se essa feminilidade almejada por Sara, estivesse disponível naquelas pílulas brancas, cuidadosamente protegidas por cartelas de plástico e disponíveis em largos e envidraçados balcões farmacêuticos. 
Dessa forma, é como se gestadinona, perlutan, estradiol, ciproterona, espironolactona e toda uma série de hormônios distribuídos nas mais diversas apresentações funcionassem como «milagrosos», guardando em sua composição química a "capacidade mágica» de fazer brotar seios, desenvolver quadris, tornear os corpos, aveludar a pele, fazendo surgir tudo aquilo que, cultural e discursivamente, aprendemos como performatividades do feminino (Butler 2003). Diante desse quadro de pensamentos, observamos claramente o quanto os hormônios, ao viabilizar essa aproximação com um suposto universo feminino, funcionam na verdade como agentes sociais e políticos que inventam possibilidades de humanidade por intermédio de tecnologias de gênero (Lauretis 1994) particulares. Os hormônios, quando inseridos no cotidiano das mulheres trans*, podem ser conceituados como fluxos que fazem parte da constituição de modos de viver particulares, vide, por exemplo, o que Leda nos conta:

Na época, era uma injeção de gestadinona que eu tomava toda semana. Com um mês, meus seios já começaram a desenvolver, e pra mim aquilo era um... ahhh... quando eu vi os seios realmente surgindo eu pensei: «realmente é isso que eu quero». (Leda)

Parece-nos que a construção dessa identidade feminina, a partir das tecnologias médicas, sejam cirúrgicas ou, nesse caso, químico-hormonais, retoma aquilo que Preciado (2008) outrora nomeou de biocapitalismo farmacopornográfico, ou seja, uma produção de corpos como interfaces tecnorgânicas, reguladas por grandes corporações em fluxos mundializados de capital, nesse caso, as próprias indústrias farmacêuticas. Nesse quadro, em que os hormônios são um importante vetor de regime de governo dos corpos, pessoas e populações, esse corpo feminino desejado acaba sendo mobilizado como mercadoria que, em sua dimensão pornográfica capitalista, age na intensificação dos prazeres pela gestão de imagens de um corpo desejável. Assim, para Preciado (2008), na atuação crescente das indústrias farmacêuticas, esses corpos declinados ao feminino são capitalizados em fluxos globais, em que o medicamento - ou mais propriamente sua magia - passa a ser vetor estruturante não só de sua feminilidade mas, inclusive, de sua viabilidade como pessoa.

Tomar o hormônio torna-se então condição para ser reconhecida como mulher trans*, especialmente no contexto das entrevistadas, em que o acesso às próteses e transformações físicas de ordem cirúrgica é mais limitado, tanto em termos financeiros, quanto em termos de mercado disponível, reclamação constante de nossas interlocutoras sobre o mercado de cirurgias estéticas em Aracaju. Assim, as experiências com os hormônios aparecem em todos os relatos como um dos primeiros passos no caminho do processo transexualizador:

Eu comecei a me hormonizar logo que eu fui expulsa de casa, aos 15 anos. Precisava trabalhar e o único caminho era a prostituição, mas aí eu precisava de um corpo mais feminino, né? (Ana) 
Eu comprava os hormônios na farmácia com minha amiga, logo no início, e até hoje, quem aplica em mim é minha mãe. (Clara)

O que abre espaço para pensar como modalidades de subjetivação, que encontram nos fármacos um dos seus vetores mais importantes, produzem sujeitos a partir de efeitos da linguagem, do imaginário, da cultura, enfim, do desenvolvimento complexo de várias tecnologias políticas e de gênero. Esses corpos hormonais e hormonizados funcionam agenciando subjetividades e modos de relacionamento consigo e com os outros, mediante fluxos que vão de técnicas biomoleculares, nos termos de Rose (2013) - a própria administração dos compostos hormonais via oral, intramuscular, transdérmica -, às imagens sensuais e pornográficas, nos termos de Preciado (2008) - a produção, mediante a agência dos hormônios, de um tipo específico de corporeidade.

Meus primeiros hormônios eu comecei a tomar com 18 anos, a partir de Catarina e Daniela, na época era gestadinona. Como não tinha médico pra atender a gente, quem orientava eram as mais antigas, né. Elas que diziam o que podia tomar, misturado com o quê. E hoje em dia tem também a Internet, que ajuda horrores. (Márcia)

Apesar da existência de alguns poucos ambulatórios especializados em hormonioterapia para pessoas trans* em cidades brasileiras e do significativo marco legal $^{2}$ que garante o acesso à hormonioterapia na rede de saúde, «os conselhos das mais antigas» e a Internet aparecem como espaços privilegiados para a troca e composição do que se nomeia de «regimes hormonais», isto é, conjuntos de combinações e dosagens de fármacos, que visam produzir novos contornos corporais e intensificar fluxos desejantes (Galindo et al. 2013). Essas redes outras constituídas, que prescindem da atuação médica formal nos consultórios, parecem funcionar como importante elemento constitutivo de um projeto de saúde despatologizante, que leva em consideração os saberes adquiridos pelas próprias pessoas demandantes dos cuidados em saúde. Há uma reconfiguração do saber médico, que é assimilado pelas «mais velhas» e então transmutado e repassado às «mais jovens» via fóruns de Internet ou os conselhos dados pelas «mais velhas» às «mais jovens», numa espécie de «rito de passagem», ou iniciação ao processo de feminilização.

Essas trocas cibernéticas de conhecimento e saberes agem na produção de corporeidades que se dão especialmente nesses ambientes digitais (Braidotti 1996). De acordo com Braidotti (1996), em contextos de intensos fluxos de informações como na Internet, as vivências de gênero se tornam diferenciadas, especialmente na medida em que, como aponta o exemplo apresentado, abre-se espaço para uma

Vide portaria n. ${ }^{\circ}$ 2.803, de 2013, do Ministério da Saúde do Brasil, que redefine e amplia o Processo Transexualizador no Sistema Único de Saúde (SUS). 
transgressão - ou, pelo menos, um deslocamento - do saber/poder (Foucault 2012). Se a medicina tradicional aponta para um «sujeito trans» único, delimitado, circunscrito e homogêneo, com um sistema de comportamento catalogável, uma existência passível de ser taxonomizada e demandante de uma terapêutica cirúrgico-hormonal (Leite e Santos 2015), as entrevistas com essas pessoas colocam em xeque o saber/poder médico em definir suas existências. Questionam os rígidos protocolos cirúrgicos e hormonais que, necessitantes de um aval psiquiátrico, enrijecem e linearizam as possibilidades de alterações corporais demandadas pelas pessoas trans*. Desconstroem a ideia de que as experiências trans* precisam ser enquadradas em uma nosografia, capturadas por um código ou encerradas em diagnósticos para que então suas vidas adquiram inteligibilidade.

Contudo, por mais que esse processo de relação das mulheres trans* entrevistadas com a hormonioterapia encene possibilidades de um projeto de saúde pautado numa retórica despatologizante, vale ressaltar que mesmo nesse contexto a medicina não deixa de expressar seu caráter regulatório. Por mais que a medicina apareça desterritorializada nesse contexto, habitando não mais os consultórios, seus sistemas de controle não deixam de existir, só porque o discurso médico toma agora outras ambiências como os fóruns de Internet. Afinal, as trocas informais, os conselhos, as informações virtuais, se constituem como uma maneira de materialização desse discurso que circula e é apropriado pelas mulheres trans* e assim funcionam também alastrando e espraiando, mesmo que de algum modo subvertido, o próprio discurso médico, que a priori pareceria abstraído.

Exemplo desse alastramento do discurso médico, que é representado com outras cores, é a produção deste «saber hereditário» que é passado de geração em geração, pelas «mais antigas» às «mais novinhas». O que, no mesmo movimento, tanto desterritorializa a endocrinologia como única produtora dos saberes sobre os hormônios, como também reitera o saber médico, absorvendo e transformando muito do que lhe é endereçado. Assim, receptores celulares, interações medicamentosas, efeitos colaterais, povoam também o vocabulário dessas mulheres trans*, só que sob outros matizes. Mesmo porque, ainda que essas relações atuem como espaços para hormonização, com tessitura «por fora» dos circuitos formais de adstrição médica, a busca por profissionais médicos não é considerada totalmente dispensável pelas entrevistadas, conforme observa Márcia:

Mas é importante a gente se cuidar, né mona, ir no médico. Claro que algumas vezes a gente não é bem atendida, muitos deles dizem que não sabem, que não podem atender; mas a gente tem que se cuidar, eu mesma faço sempre a mamografia. (Márcia)

Por fim, seja na produção desse feminino almejado, seja nas relações particulares que cada entrevistada tece com relação a esses circuitos, o que observamos é o quanto essas substâncias e seus efeitos agenciam os corpos e os modos dessas pessoas se relacionarem com os outros. O quanto os hormônios estabelecem fluxos 
que, atravessados por todo um investimento do capitalismo industrial - notavelmente na forma das indústrias farmacêuticas, observadas por Preciado (2008) que transformou o gênero num objeto privilegiado de gestão pública, movimentam novos tipos de governabilidade dos seres vivos, convertendo corpos e gêneros, constituídos quimicamente, no centro da atividade política e econômica.

\section{Mitos, misticismos, magias, alquimias e bruxarias}

Dizem que, na França medieval, um médico chamado Paracelso - discípulo direto do grande alquimista Nicolas Flamel - já propunha o uso de alguns elementos químicos para produzir medicamentos. Diferente de seu mestre, que passou a maior parte de sua vida preocupado com a pedra filosofal, com o elixir da longa vida e com a transmutação de metais em ouro, Paracelso postulava que a Alquimia tinha como intuito real servir como instrumento auxiliar no restabelecimento da saúde, sendo utilizada como base para o preparo dos medicamentos minerais, por meio de técnicas alquímicas de separação e purificação. Assim, antecipou muito dos princípios da homeostasia, da farmacologia e das propriedades físico-químicas de muitas substâncias (Hutin 2010).

Parece-nos, sem espanto, que os hormônios revisitam esse universo da magia, da alquimia e do misticismo. Seja pelas alterações visíveis que provocam, seja por uma série de discursos e fábulas que atravessam o seu uso. Afinal, uma substância que tem a capacidade quase mágica de transformar o corpo e borrar as fronteiras de algo que construímos com tanto cuidado e esforço - no caso, as fronteiras de gênero -, não poderia fugir dessas fabulações que lhes são endereçadas. Uma delas é a figura do «nervoso» mostrada por Ana:

Os hormônios eu compro, normalmente, na farmácia, só que tem uns que dá muita reação no psicológico, fica suando as mãos e os pés, fico muito nervosa. Eu até cheguei a ir ao médico, aí eu fiz os exames, perguntei se tinha problema. Eu já fui muito mais hormonizada, mas como eu trabalho com as anatomias humanas, tem que usar o pênis, né, e eles fazem questão de pegar uma mulher com o pênis duro. (Ana)

A ideia do «nervoso» causado pelo uso dos hormônios, expressa por Ana, foi unanimidade entre as entrevistadas e também pode ser observado nos trabalhos de Pelúcio (2005) com as travestis paulistas. Contudo, muito mais do que um pretenso efeito colateral secundário ao (ab)uso dos hormônios, esse «nervoso» funciona não só atualizando a aura mágica que atravessa o uso dos hormônios - afinal toda magia tem um pouco de consequência - mas também funciona como engrenagem dessa tecnologia químico-corporal que materializa uma rede de discursos sobre esses corpos, constituindo-se, assim, como mito estruturante e constitutivo da própria experiência como mulher trans* . Afinal, não se tem acesso ao sentido atribuído 
a ele sem que antes haja uma significação cultural da própria ideia do que é esse «nervoso» e que, portanto, torne esse mito possível. Essa significação cultural revisita a ideia de irritabilidade e de instabilidade atribuída à relação «própria do feminino» com os hormônios, mais especialmente à figura da mulher histérica, constituída pela psicanálise freudiana do início do século xx. Dessa forma, tornar-se mulher associa-se a essa ideia de «nervoso», de instabilidade emocional, oriunda dos processos fisiológicos hormonais de seus corpos, conectando assim fisiologia e endocrinologia ao mundo do simbólico, da cultura e da política.

Processo esse de contaminação, que não se interdita aí. Outro dos «poderes mágicos» dos hormônios, além de mexer com a estrutura física e psicológica das mulheres trans*, é aquele que atravessa as construções sobre seus prazeres. Um exemplo claro é a reclamação de Ana sobre a diminuição de sua libido com o uso dos antiandrogénos, o que inclusive chega a atrapalhar seu trabalho na prostituição. Mais uma vez, não são só supostos efeitos colaterais químicos que estão em jogo, não é simplesmente uma diminuição da libido, como se isso encerrasse em si um mero fenômeno orgânico. O que está em jogo é um gerenciamento e uma construção do corpo das mulheres trans* como se a elas não fosse possível o direito de sentir prazer. Historicamente, a medicina estabeleceu, desde os tratados de Harry Benjamin (1966) sobre o «fenômeno transexual», que uma característica marcante das experiências de mulheres trans* seria justamente o sentimento de desprazer e repulsa sobre seus corpos. Contudo, fissuras despontam nesses corpos dissidentes, seja quando elas precisam do pênis para trabalhar, como enuncia Ana, ou porque elas requerem o direito de usá-lo e de sentir prazer, como Leda assinala, ao dizer que, quando um homem lhe está fazendo sexo oral, ela imagina que ele está chupando seu «clitóris de $20 \mathrm{~cm}$ ».

Todavia, a magia é algo da ordem do imaterial e que, muitas vezes, escorre pelos dedos, quando os rituais não são devidamente representados. Nesse sentido, Clara aponta que:

Tem um tabu entre nós transexuais de que quando nós tomamos hormônios e ejaculamos, o hormônio sai todo na ejaculação. Se eu ejaculo hoje, eu já olho pra minha mão e vejo um monte de veia, aí me dá uma agonia, vixe! Tô precisando de hormônio urgente. (Clara)

Da mesma forma que os hormônios trans*formam e fazem pessoas, eles também, dado seu caráter mágico, vão embora, caso o encanto se quebre. A fala de Clara mostra o quanto essas tecnologias químico-corporais atuam na produção de um feminino idealizado, por meio de rituais tanto mágicos, quanto (al)químicos, seja na produção de um feminino através da alteração física, seja através das interdições colocadas pelos mitos e simbologias em torno da correta utilização e gerenciamento desses hormônios. Esse exemplo trazido por Clara se conecta ao que foi trazido por Ana e refere-se, sobretudo, a uma regulação dos prazeres e dos desejos 
das mulheres trans* que, mesmo que se queiram estabilizar quimicamente, estão em constante fluxo e deslocamento, sendo definidos e redefinidos ao longo do processo de hormonização. Assim, como a magia do hormônio, o gênero parece ser sintético, maleável, variável e suscetível de ser transferido, imitado, produzido e reproduzido (Lauretis 1994).

Para além desses efeitos particulares e desses mitos construídos acerca do uso dos hormônios, parece-nos que a estrutura mágica é algo que não apenas perpassa essa relação das mulheres trans* com os hormônios, mas que permeia todo o aparato da saúde. Os discursos, endereçamentos, rituais e mitologias que atravessam o uso dos hormônios e suas consequências também podem ser encontrados em outros âmbitos da saúde. Os pânicos que cercam algumas doenças, os temores que se têm sobre a anestesia, os mitos construídos sobre um potencial salvador das cirurgias, as fábulas que se constroem em torno da alimentação, etc. De tal modo, a própria relação de desterritorialização que as mulheres trans* estabelecem com o aparato médico parece não só apontar as fragilidades desse modelo, pautado no paradigma biologicista (Camargo Jr 2005), mas também oferece pistas para se pensar uma prática médica não apenas centrada no diagnóstico de patologias e na prescrição de condutas, na maioria das vezes, medicamentosas. Ao contrário, apresenta possibilidades de um fazer que contemple o outro no processo decisório e que prescinda da hegemonia do estatuto da patologia para pensar suas experiências como agentes e não meramente pacientes (e, portanto, sujeitas aos regimes de verdade da medicina).

\section{Para pensar outros modos possíveis em saúde}

Não é de todo estranha essa relação da saúde com o universo do místico. Basta que revisitemos as linhas da medicina chinesa, as agulhas da acupuntura, os rituais xamânicos das regiões africanas, etc. Entretanto, por mais que esses exemplos se mostrem tão claros, parece que a Norte e a Oeste essa saúde se transforma e, para representar fidedignamente o espírito ocidental, se despoja de tudo aquilo que pode parecer pouco científico. Daí extirpar - ou pelo menos tentar - todo e qualquer resquício de magia de seus fazeres.

Contudo, de modo algum, essa relação da saúde com o universo do místico habita apenas uma parte do orbe terrestre; ela atravessa também isso que se tem chamado de medicina ocidental contemporânea. A relação das mulheres trans* com os hormônios funciona como uma alegoria simbólica deste misticismo, apontando o quanto o aparato médico é regulado e perpassado pelo insondável. Possibilitando que, assim, pensemos outras formas de contaminação da saúde pela magia ou, dito de uma melhor forma, evidenciando o quanto, desde sempre, já é a própria saúde em sua relação com o outro atravessada por alquimias, misticismos e bruxarias. 
Ao propor essa contaminação mística, possibilitando pensar temas como desterritorialização de posições de poder, mitos que atravessam os cuidados em saúde e a produção de subjetividades por meio de tecnologias farmacológicas, podemos ampliar essas possibilidades para outros espaços que, assim como as experiências trans*, se encontram resumidos a protocolos clínicos, orientações epidemiológicas e formatações patológicas. Desta forma, o fazer do campo da saúde pode criar novos campos de inteligibilidade, novas narrativas possíveis, ao abrir espaço para se pensar o outro também como agente nos cuidados em saúde, borrando as fronteiras de gênero ao despatologizar e pluralizar as existências trans*.

Desse modo, o exercício que aqui encenamos pode facilmente ser transposto para outras esferas de atuação médica, revelando outros modos possíveis dos fazeres em saúde. Podemos, a partir desses marcos, pensar o pânico moral sobre as pessoas em (ab)uso de drogas, os estigmas às pessoas em situação de prostituição, a infantilização dos considerados «enfermos mentais», a prática de culpabilização de pessoas acima de um determinado padrão de peso, a violência obstétrica a que muitas gestantes são submetidas e, de um modo geral, a falta de autonomia e protagonismo de diversos «pacientes» e sua cooptação pelo mercado farmacêutico.

Em suma, o que propomos é um olhar da saúde que desmitifique, conheça e reconheça as múltiplas formas de existir e resistir das pessoas trans* ${ }^{*}$, como afirmou Butler, em entrevista à Revista Têtu:

A vida não é a identidade! A vida resiste à ideia de identidade. É necessário admitir a ambiguidade. Frequentemente, a identidade pode ser vital para enfrentar uma situação de opressão, mas seria um erro utilizá-la para não afrontar a complexidade. Não podes saturar a vida com a identidade. (Butler 2008)

\section{Referências bibliográficas}

Benjamin, Harry. 1966. The Transsexual Phenomenon. New York: Julian Press.

Braidotti, Rosi. 1996. "Cyberfeminism with a Difference». Disponível em http://www.let. uu.nl/womens_studies/rosi/cyberfem.htm [Consultado em 8 de março de 2018].

Browne, Kath, e Catherine Nash. 2010. «Queer Methods and Methodologies: An Introduction». In Queer Methods and Methodologies: Intersecting Queer Theories and Social Science Research, editado por Kath Browne e Catherine Nash, 1-24. Surrey: Ashgate.

Butler, Judith. 2003. Problemas de gênero: feminismo e subversão da identidade. Rio de Janeiro: Civilização Brasileira.

Butler, Judith. 2008. «Entrevista a Butler y Beatriz Preciado». Entrevista realizada por Ursula Del Aguila». Têtu 138. Disponível em: https://artilleriainmanente.noblogs.org/post/ 2016/04/15/judith-butler-y-beatriz-preciado-en-entrevista-con-la-revista-tetu/ [Consultado em 8 de março de 2018].

Camargo Jr, Kenneth Rochel. 2005. «A Biomedicina», Physis 15: 177-201. DOI: https://doi. org/10.1590/S0103-73312005000300009 
Foucault, Michel. 1996. A ordem do discurso. São Paulo: Loiola.

Foucault, Michel. 2005. A arqueologia do saber. Rio de Janeiro: Forense Universitária.

Foucault, Michel. 2009. História da sexualidade I: a vontade de saber. Rio de Janeiro: Edições Graal.

Foucault, Michel. 2012. Microfísica do Poder. Rio de Janeiro: Graal.

Galindo, Dolores, Ricardo Méllo, e Renata Vilela. 2013. «Modos de Viver Pulsáteis: navegando nas comunidades Trans sobre hormônios». Revista Polis e Psique 3(2): 19-42. Disponível em https://seer.ufrgs.br/PolisePsique/article/view/42290

Hutin, Serge. 2010. História Geral da Alquimia. São Paulo: Editora Pensamento.

Larrosa, Jorge. 1994. «Tecnologias do eu e educação». In O sujeito da educação: estudos foucaultianos, organizado por Tomaz Tadeu Silva, 35-86. Petrópolis: Vozes.

Lauretis, Teresa. 1994. "A tecnologia do gênero". In Tendências e impasses: o feminismo como crítica da cultura, organizado por Heloisa Hollanda, 206-242. Rio de Janeiro: Rocco.

Leite, André, e Claudiene Santos. 2015. «Taxonomizando sujeitos: notas sobre os investimentos dos sistemas classificatórios psiquiátricos na regulação das transexualidades e travestilidades». Interfaces Científicas 4(1): 88-99. DOI: https://doi.org/10.17564/2316-3801.2015v4n1p88-99

Pelúcio, Larissa. 2005. «Toda Quebrada na Plástica: corporalidade e construção de gênero entre travestis paulistas». Campos 6: 97-112. DOI: https://doi.org/10.5380/cam.v6i0.4509

Platero, Raquel Lucas. 2014. Trans*exualidades: Acompañamiento, factores de salud y recursos educativos. Barcelona: Bellaterra.

Preciado, Beatriz. 2008. Testo yonki. Madrid: Espasa.

Reis, Cristina. 2012. «O uso da metodologia queer em pesquisas no campo do currículo». In Metodologias de pesquisas pós-críticas em educação, organizado por Dagmar Meyer e Marlucy Paraíso, 49-69. Belo Horizonte: Mazza Edições.

Rose, Nikolas. 2013. A política da própria vida: biomedicina, poder e subjetividade no Século XXI. São Paulo: Paulus.

Tompkins, Avery. 2014. Asterisk. Transgender Studies Quaterly 1, pp. 26-27.

André Filipe dos Santos Leite. Médico pela Universidade Federal de Sergipe. Pós-graduando em Psiquiatria pela Universidade Estácio de Sá. Integrante dos Grupos de Pesquisa: Gênero, Sexualidade e Estudos Culturais (GESEC/UFS/CNPq) e Clínica Psicanalítica e Cultura Contemporânea (GPCPCC/UFS/CNPq).

Endereço eletrônico: andrefsleite@yahoo.com.br

Claudiene Santos. Doutorada em Psicologia pela FFCLRP/USP. Docente do Programa de Pós-Graduação Interdisciplinar em Cinema e Narrativas Sociais (PPGCINE) e do Curso de Biologia da Universidade Federal de Sergipe. Líder do Grupo de Pesquisa: Gênero, Sexualidade e Estudos Culturais (GESEC/UFS/CNPq). Integrante dos Grupos de Pesquisa Salud, Inclusión y Pedagogía (SIP/UAM); Xique-Xique: Grupo de Pesquisa sobre Gêneros e Sexualidades (UFS/CNPq) e Sexualidade Vida (USP/CNPq). Endereço eletrônico: claudienesan@gmail.com

Artigo recebido em 17 de maio de 2018 e aprovado para publicação em 30 de junho de 2018. 